\title{
地理信息公共服务平台模式探讨
}

伍素贞

广东省地质测绘院

DOI:10.32629/gmsm.v2i2.116

[摘 要] 现阶段,我国地理信息公共服务平台发展最大的问题就是维护和更新。当前,地理信息公共服务平台主要包括信息集 中存放和集中维护、以及分布维护和集中存放、分布存放和分布维护三种模式。这三种模式的建立可以更好解决地理信息公 共服务信息的维护问题,必须建立健全基于分布维护公众和政府以及企业三者共存的地理信息服务机制,促进我国地理信息公 共服务平台的良好建立。

[关键词] 地理信息; 公共服务; 模式

随着我国计算机技术的快速发展, 地理信息系统逐渐完 善。在信息技术的支持之下, 进一步优化和完善地理信息系 统需要更高的技术要求。在现代地理信息公共服务平台的影 响之下, 计算机测绘技术出现得到大范围的使用。比如航空 遥感技术和全球定位系统等等, 还包括数字栅格地图等 “ $4 \mathrm{D}$ ” 数字产品, 这些信息技术在一定程度上改变了原先测绘数据 的获取方式和呈现形式, 使得地理测绘服务提高到了的新的 高度, 对于提高我国地理信息公共服务测绘的水平有着重要 的意义。

\section{1 地理信息公共服务平台的三种模式}

1.1 信息集中存放和维护的模式

当前在地理公共服务平台中信息集中维护的模式是最 为普遍的方式, 这种模式主要出现在我国最早的搜狗地图当 中, 也就是现在 “图行天下”, 这是我国最早的给人们提供出 行服务的在线地图服务系统, 这一网站有非常完整地地图浏 览功能, 广大用户在汶览的时候可以实现平移和缩放以及移 动等功能。此外, 还可以在提供信息查询的功能, 比如广大用 户在网站上输入一个地区, 该网站就可以给用户提供许多信 息, 或者是点击图上的要素查询属性, 提供空间分析和路径 分析功能。比如驾驶路线以及途径的地点等等。随着我国地 理信息服务的不断完善, 我国相机出现了百度地图搜索、高德 地图等等的专业性在线服务。比如 $\mathrm{E}$ 都市的 www. edushi. com 就 是当前世界第一个使用三维地图的城市。三维地图除了提供公 交线路之外, 在线功能很多, 还提供旅游路线和交通路线以 及道路景点查询等等, 人们在家中就可以看到一些大城市的 风景。但是该三维地图的缺点是成本比较高, 信息更新比较 之后, 很难推及大众服务。

1.2 信息集中存放与分布维护的模式

一些Web 网站为了降低维护成本, 缩短周期, 发展了许 多维护数据的功能, 从而及时维护和更新城市的信息。比如
百度地图在网页上出现的标注功能, 就是让广大用户在使用 百度地图的时候, 可以进入详细的界面找到地图纠错系统, 并填写正确地的信息提交即可。比如厦门的鹰图公司就是专 门为了服务公共事业为研发设计的, 当前, 鹰图国内公司在 的应用范围非常广阔, 不仅可以服务电网规划行业, 而且还 可以用于客户服务抢修和安全应急处理。当前, 此分布式维 护的模式已经为企业和政府的地理信息服务平台提供支持, 大大实现了地理信息的优化整合和资源共享。

1.3 信息分布存放和维护的模式

信息分布存放和维护的模式为了改变传统过于集中的 存放模式, 是为了更加有效地应对地理信息的存放问题。当 前, 在这种分布存放的方式得到广泛的应用。实践证明, 其可 以大大提高信息整理的有效性,使得搜集信息更加方便。在 传统的信息维护当中, 因为信息存放的方式比较集中, 使得 维护地理信息相对困难。因此,地理信息公共服务必须制定 单独的数据库, 从而为各个行业的发展提供强大的技术支 撑。让地理信息数据库可以正常稳定的进行。

\section{2 地理信息公共服务平台的作用}

2.1 不断完善地理信息公共服务平台

随着信息时代的快速发展, 在国民经济发展过程中信息 自动化发挥的作用越来越重要。地理信息公共服务平台的不 断优化可以帮助各个行业快速地掌握资源, 获得大量有效地 信息, 从而掌握市场发展的主动权, 提高自身在行业竞争中 的筹码。

\section{2 促进经济结构调整}

完善地理信息共同服务平台对于优化调整经济结构有 着重要的现实意义, 从而促进社会加快建立和完善地理公共 信息服务平台。借助信息平台, 借助地理信息人才和相关的 法律法规, 加快基础地理信息技术产业的快速发展。在地理 信息公共服务平台的建设中必然会使用计算机信息技术和 
通信技术以及网络等相关产业的进步, 促进政府转变经济职能, 完善民主法治的建设。同时还可以促进企业优化调整产业结构, 减少企业资源消耗，促进地理信息资源的可持续发展。

\section{3 促进社会信息化建设}

完善地理信息公共服务平台对于促进社会信息化建设 有着重要的作用。地理信息公共服务平台可以实现数字信息 化和网络化以及智能化资源的整合, 广泛收集和更新地理信 息。同时还可以调整资源的动态整合, 帮助各个行业更好地 进行信息决策, 从而推动社会信息化建设的发展, 改造和升 级传统的产业, 实现产业的夸跨越式发展。地理信息公共平 台涵盖的内容非常多, 可以更加直观地反应多方面的问题和 内容, 集中体现我国科技以及经济和法治建设的发展程度。 实现各种信息的检索，建立完备地地理信息公共服务平台。 同时, 地理信息公共服务平台还可以地信息进行可视化的智 能处理。因此, 完善的地理信息公共服务平台可以道帮助各 个行业提高决策的速度, 为企业更好地决策提供给依据。从 而更加高效地利用已经存在的地理信息资源制定科学合理 的战略的决策, 实现社会发展与生态环境的平衡发展, 逐渐 缩小各个区域的经济发展差距。特别是对于一些突发的时间, 地理信息共同服务平台可以做出及时处理, 并在各个部门中 发挥重要得到作用, 拓展产业领域。不得不说, 地理信息公共 服务平台是一个蓬勃发展的 “朝阳”产业。

\section{3 完善地理信息公共服务平台模式的相关建议}

3.1 加强政府的主导和支持

地理公共服务平台的建设与发展需要政府的支持和主 导, 建立以数字化为平台服务体系, 真正做到服务大众、服务 社会、服务民生。总得来说, 地理信息公共服务平台的建设 实施的是 “一站式” 的服务模式, 通过信息资源的会互相联 结, 实现社会进步和经济发展的信息化进程, 促进各个行业 可以在测绘行业中快速进入信息化发展道路之上。

\section{2 建立数据保密机制}

计算机信息网络的发展需要计算机服务的支撑, 同时还 需要加强数据的保密, 让地理信息公共服务平台上的数据可 以更加安全, 避免因为外界的恶意攻击而出现数据网络㿈疾 等等。因此, 地理信息共同服务平台在建立的时候必须建立 完善的数据保密制度,这不仅仅是为了保护地理信息共同服 务平台的数据, 而且还是为了建立相应的地理信息数据机制, 从而实现地理信息数据之间可以实现相互的联系, 保证地理 信息公共服务平台在共享数据的时候可以不会受到外界事 物的影响, 保证地理信息数据可以正常而完整地传输。

3.3 建立数据地理信息公共服务平台的更新机制

地理信息公共服务平台是建立在广大用户的基础上进 行的, 如果没有广大用户的支持, 地理信息公共服务平台也
将不会存在。因此, 地理信息公共服务平台必须保证地理数 据的及时和准确, 这是当前地理公共服务平台需要解决的关 键问题。因此, 地理信息公共服务平台的后台服务器必须及 时更新地理信息数据, 一旦发现后台出现问题, 必须及时更 改。由此可以看出, 建立健全地理信息公共服务平台的更新 机制非常有必要。在建立更新机制的过程中可以与其他地理 信息服务平台加强沟通与联系, 实现有效地传递信息、分析 地理信息和处理地理信息, 避免因为信息更新不及时导致平 台出现㿈疾。在平台模式建设的过程中, 每一个节点和基地 的建设都应当及时地获取信息从而及时更新数据, 这对于整 个地理信息公共服务平台的建设非常关键。因此, 平台模式 在分建共享的时候, 每一级的节点和信息基地必须明确数据 更新的范围, 对于各个级点政府可以加大管理, 建立完善的 法律法规。最关键的是, 地理信息公共服务平台的模式的更 新应当做好应急更新和日常更新, 全方位、多角度地做好得 数据更新。

地理信息共同服务平台数据的更新不仅仅可以体现数据 的有效性, 而且还可以为处理突发事件提供准确的数据。在危 机的时刻准确的数据可以发挥强大的意义与作用。但是, 现阶 段, 地理信息公共服务平台对于及时更新数据不及时。因此, 还 需要政府和相关部门大力支持地理信息公共服务平台的建设, 不断加大经济投入, 及时解决地理信息公共服务平台中存在的 问题, 从而为政府做出科学的决策提供参考依据。

\section{4 结语}

综上所述, 当前我国地理信息公共服务平台模式的建设 已经取得了重大的进展, 通过各种推动力的影响之下, 相关 的部门根据自身的需求实现优势互补, 一起为推动地理信息 公共服务平台的良好发展做出了巨大的贡献。

\section{[参考文献]}

[1]张健峰,王代壁,周海鹏.省级时空信息云平台建设方 案研究与应用——以新疆基础地理信息时空云平台建设为 例 [J].测绘与空间地理信息,2019,42(02):76-79.

[2]刘彦。矿区地下管线地理信息公共服务平台建设模式 探讨[J].世界有色金属,2018,(21):296+298.

[3]崔巍.浙江省数字城市地理空间框架建设运维的研究 探索[J].地理信息世界,2018,25(06):25-30.

[4]王环璐,吕欢欢,张峻通,等.基于Mashup 技术的房产信息网 上查询系统设计与实现[J].软件导刊,2018,17(12):122-125.

[5]杨靓,黄蔚.打开丝路的窗口一一天地图服务“一带一 路”建设综述[J].中国测绘,2018,(06):10-13.

[6]冯振俭,侯祥意.基于 EPS 平台的国土内外业一体化平 台设计与实现[J].企业科技与发展,2018,(10):104-107.

[7]绕鸣.地理信息公共服务平台建设与现代测绘服务模 式的研究[J].信息系统工程,2018,(08):29. 